OPEN ACCESS

Edited by:

Patrik Sörqvist,

Gävle University College, Sweden

Reviewed by:

Francesco Aletta,

University of Sheffield, UK Andrés Di Masso,

University of Barcelona, Spain

${ }^{*}$ Correspondence:

Ferdinando Fornara

ffornara@unica.it

Specialty section:

This article was submitted to

Environmental Psychology,

a section of the journal

Frontiers in Psychology

Received: 18 May 2016

Accepted: 08 August 2016 Published: 02 September 2016

Citation:

Fornara F, Dentale F, Troffa $R$ and Piras S (2016) Measuring Implicit

European and Mediterranean Landscape Identity: A Tool Proposal.

Front. Psychol. 7:1259.

doi: 10.3389/fpsyg.2016.01259

\section{Measuring Implicit European and Mediterranean Landscape Identity: A Tool Proposal}

\author{
Ferdinando Fornara ${ }^{1,2 *}$, Francesco Dentale ${ }^{3}$, Renato Troffa $^{1}$ and Simona Piras ${ }^{1}$ \\ 'Department of Education, Psychology, Philosophy, University of Cagliari, Sardinia, Italy, ${ }^{2}$ Centro Interuniversitario di Ricerca \\ in Psicologia Ambientale - Interuniversity Research Center in Environmental Psychology, Rome, Italy, ${ }^{3}$ Department of \\ Psychology, Sapienza University of Rome, Rome, Italy
}

This study presents a tool - the Landscape Identity Implicit Association Test (LIIAT) - devoted to measure the implicit identification with European and Mediterranean landscapes. To this aim, a series of prototypical landscapes was selected as stimulus, following an accurate multi-step procedure. Participants $(N=174)$, recruited in two Italian cities, performed two LI-IATs devoted to assess their identification with European vs. Not-European and Mediterranean vs. Not-Mediterranean prototypical landscapes. Psychometric properties and criterion validity of these measures were investigated. Two self-report measures, assessing, respectively, European and Mediterranean place identity and pleasantness of the target landscapes, were also administered. Results showed: (1) an adequate level of internal consistency for both LI-IATs; (2) a higher identification with European and Mediterranean landscapes than, respectively, with Not-European and Not-Mediterranean ones; and (3) a significant positive relationship between the European and Mediterranean LI-IATs and the corresponding place identity scores, also when pleasantness of landscapes was controlled for. Overall, these findings provide a first evidence supporting the reliability and criterion validity of the European and Mediterranean LI-IATs.

Keywords: landscape identity, place identity, European identification, Mediterranean identification, implicit association test

\section{INTRODUCTION}

\section{Identification with Landscapes}

The psychological responses to the landscapes represent an issue widely investigated in the literature, with a particular focus on the patterns of affective and esthetic evaluation (see Kaplan and Kaplan, 1989; Kaltenborn and Bjerke, 2002). This perspective taps the so-called "subjective" assessment of landscapes, which in fact concerns the perceptual side, and is contrasted to the "objective" assessment of landscapes, which addresses their capacity to provide a set of benefits for the ecosystem (see Aretano et al., 2013). Within the "subjective" domain, that is the focus of this paper, a substantially unexplored field is the identitarian meaning of landscapes, which refers to their image as a potential source of (shared) identification for a given community. In this regard, Hagerhall (2001) pointed out that the Swedish traditional cultural landscape, including pastures and meadows, has assumed a prominent position in the national history, being also frequently portrayed in Swedish literature and art. Hence, it is thus not surprising that this kind of images is 
used for advertising goals (Hagerhall, 2001), in order to convey messages that should connect the positive connotation evoked by the landscape to the self-identity of persons who identify with it.

The present study proposes a tool for measuring the implicit identification with those landscapes referring to broad geographical scales represented by the European continent and the Mediterranean area. In fact, we assumed that those persons living in the European and Mediterranean zone could consider these two targets as meaningful places.

Landscape identity is here conceived as a specific component of place identity, that is a concept originally developed by Proshansky et al. (1983, p. 60), who defined it as "a set of memories, conceptions, interpretations, and feelings related to a specific physical setting." In other words, place identity is conceived as a component of the self-concept referring to the place one belongs to Hernández et al. (2007) and Lewicka (2010). More specifically, this construct concerns "those dimensions of the self that define the individuals' personal identity in relation to the physical environment, by means of a complex pattern of conscious and unconscious ideas, beliefs, preferences, feelings, values, goals, behavioral tendencies, and skills relevant to this environment" (Proshansky, 1978, p. 155). Landscapes may be considered as important sources of identity, as they embody not only environmental identification processes but also social meanings (Twigger-Ross et al., 2003). In this view, for instance, on the basis of the ingroup bias effect postulated by the Social Identity Theory (SIT: Tajfel and Turner, 1986), the membership in social groups that are located in a specific place (i.e., a setting delimited by spatial-physical boundaries) may in fact represent a support for the maintenance of a positive place identity (Carrus et al., 2014).

Different conceptual paths have been followed in order to investigate the relationship between place and identity patterns. Some studies focused primarily on the identification with a place and on the attributes that give a distinctive place identity to the residents (e.g., Schneider, 1987; Uzzell et al., 2002). In other studies, the identity of the place is conceived as a facet of personal and social identity (i.e., a "localized" social identity) that stems from processes of identification, social cohesion, and residential satisfaction (Valera and Pol, 1994). In this vein, the extent to which individuals identify themselves with a prototypical landscape is expected to be related to the degree of their community identification. Place identity patterns have typically been studied at different levels of scale, such as local (e.g., urban identity, see Lalli, 1992; Valera et al., 1998; Bonnes et al., 2011), regional (e.g., Abrams and Emler, 1992; Carrus et al., 2005), and national (e.g., Smith, 1992) scale. Instead, here we focus on a supranational level, given that our target places are, respectively, "Europe" and "Mediterranean," both representing socially constructed entities which include geographical, social, and political meanings.

In fact, we acknowledge that images of our city or specific sites of our country are part of our local or national identity, but what about landscapes concerning identity targets at a broader scale in geographical terms, such as for example Europe and Mediterranean? Do prototypical images of Europe and the Mediterranean, typically not so much salient in our daily life, play a role in enhancing identification patterns at a broader geo-cultural scale?

\section{European and Mediterranean Identities}

Europe and Mediterranean are geographical notions that present different characters, since the latter is outlined by marked physical boundaries (i.e., those countries "touched" by the Mediterranean Sea) whereas the former is a complex entity in continuous change (Guarracino, 2007). Both notions include historical, political, social, and economic features.

At the European level, policy actions have been conducted from past centuries, since from the times of the Roman Empire (see Dinan, 2004), in order to build up supranational bodies and overpass economic and political barriers. The increased diffusion of the European currency and the continuous expansion of the political union represented a cornerstone of this process. Nevertheless, the feeling to be a European citizen as well as the development of a European identity seem rather far to be achieved, as showed by the results of anti-Euro/antiEU parties at the last elections for the UE Parliament in the 2014 as well as in the more recent national and local elections in various EU countries. Indeed, the development of a European identity should be a key element in order to overcome cultural, economic, social, political, linguistic, and religious barriers between EU nations that historically have determined conflicts and wars. As stated by Habermas (1998), who invokes "unity in diversity," the unique variety of landscapes in Europe - reflecting a common geography, history and culture - may be useful to strengthen the European identity, as a way for stressing common characteristics but respecting differences among nations. According to Stanners and Bourdeau (1995), despite the dramatic socio-economic changes that have accompanied the wave of industrialization and urbanization of the last century in Europe, most differences remained, giving a distinctive character to countries, regions, and municipalities. The first environmental assessment, carried out by the European Agency for the Environment, showed that the European continent is characterized by a great variety of landscapes, which have been shaped through a long and intense interaction between biophysical and cultural factors (European Environment Agency, 2011). The various environmental conditions, in terms of slope of the soil, topography, and climate, as well as the different religious and ideological traditions, give form to the wide variety of European landscapes, which thus have become an essential feature of cultural identities. In this sense, landscape refers to the relationship between people and place, including how natural and cultural facets of the environment interact together, and how people perceive such facets (European Landscape Convention, 2000).

As regards the Mediterranean notion, it refers to a common environment that merges together those individuals, living in different cultures, bordering on the geographic region of the Mediterranean Sea (Fabre, 1998; Aubenas and Benasayag, 2002). It represents a unique environment, which generated and fed different cultures over the millennia (Petruzzellis and Craig, 2014), and possesses a distinctive trait that goes beyond 
the concepts of regionalism, local roots, ethnocentrism, and nationalism (Cassano, 1998). In this regard, the Mediterranean identity can be seen as the result of a millennial stratification of diasporas that has produced mixed cultures and habits, and the current migration from the south to the north is a sort of continuation of ancient movements (Tarrius, 1992). To better understand the relationship between the roots of Mediterranean cultures, Petruzzellis and Craig (2014) carried out a comparative analysis of identity patterns by interviewing inhabitants of three countries bordering the Mediterranean, that is France, Italy, and Spain. Respondents revealed a common identity related to their proximity to the Mediterranean Sea, suggesting the presence of bonds that transcend political boundaries. The Mediterranean essence, shaped by the Mediterranean Sea, is represented in residents' narratives by mild climate, physical traits of the inhabitants (e.g., hair or skin color), slow and relaxed lifestyle, warmth, bright colors, symbols such as the kitchen or the dinner table, and crops like olive trees and vineyards. In Spanish and French respondents the landscape representations of the Atlantic Ocean and of the Mediterranean Sea were different: in fact, the first is perceived as dark, strong, wavy, and menacing, whereas the second is seen as bright, calm, quiet, and cozy. These different landscape images recall the distinction highlighted by Cassano (1998), who claimed that the Mediterranean is not an "empty" sea as the Ocean, but rather a basin that interconnects different lands, thus making possible a rich network of relationships (Petruzzellis and Craig, 2014). Not surprisingly, Italian and Spanish interviewees showed in their words more evident Mediterranean roots than the French ones, probably for the closeness of the latter, both geographically and culturally, to the Central and Northern Europe countries.

In conclusion of this literature review on European and Mediterranean identities connected to landscapes, it is to highlight that, despite the supposed role of such identities for creating and shaping positive psychological responses with important community implications, there is a substantial lack of empirical research on the European and the Mediterranean identity. This was one of the drivers of our study.

\section{Promoting the Use of Implicit Measures of Place Identity and Related Constructs}

An array of tools has been proposed to measure constructs concerning the identification with places and other environmental targets, such as place identity (e.g., Hernández et al., 2007), place attachment (e.g., Lewicka, 2008; Fornara et al., 2010), and identification with nature (e.g., Schultz, 2001; Clayton, 2003; Mayer and Frantz, 2004).

As well as other self-report measures, these tools are exposed to two typical weaknesses: the proneness to response biases due to impression management effects (Paulhus, 1991; Vecchione et al., 2014) and the impossibility to tap all construct-related information using introspection (Nisbett and Wilson, 1977), for both self-deception (Paulhus, 1991) and cognitive factors (Hofmann et al., 2005; Dentale et al., 2012). Recently, mono and dual models of social cognition, which distinguish implicit and explicit processes, were developed and empirically supported (see Gawronski and Payne, 2010, for a review). Interestingly, they provided an important conceptual framework to address the factors that may threaten the validity of self-report measures, such as impression management responding and introspective limits. Following this line of reasoning, many attempts have been conducted to develop reliable and valid implicit measures of psychological constructs. Among them, the most popular and tested is the Implicit Association Test (IAT), first developed by Greenwald et al. (1998) and successively used in many areas of psychological research, such as attitudes, stereotypes, and selfesteem. Classical IAT is a time reaction task that permits to assess the degree to which subjects associate two target categories (e.g., Blacks vs. Whites) with two target attributes (e.g., Positive vs. Negative).

Even though IAT procedures have been typically used in many social domains (Nosek et al., 2005), there are also a few examples in the environmental field, with reference to the energy sources (Truelove et al., 2014) and to the identification with nature (Schultz et al., 2004). In the second case, which is closer to our study object, Schultz et al. (2004) developed the "IAT-Nature" in a study about the relationship between implicit and explicit connectedness with nature. It was found that the implicit attitude has a positive correlation with the biospheric concern, and a negative correlation with the egoistic concern. Similar results about the relationship between implicit and explicit attitudes toward nature emerged in more recent studies (Schultz and Tabanico, 2007; Brügger et al., 2011; Olivos and Aragonés, 2013).

\section{Objective and Hypotheses}

This study aims at evaluating the psychometric properties and the criterion validity of two IATs devoted to measure European and Mediterranean Landscape Identity. In order to do this, different kinds of scenarios, reflecting a supranational geopolitical scale, were used as stimuli for the attribute categories (i.e., European $v s$. Not European for the first IAT; Mediterranean vs. Not Mediterranean for the second IAT), whereas a series of words were used as stimuli for the target categories (Self $v s$. Other). In particular, four types of prototypical landscapes were selected, using a three steps procedure (see next section). These Landscape Identity IATs (LI-IATs) allow to measure the degree to which European and Mediterranean landscapes are automatically associated with the self-concept.

Four specific hypotheses were tested to evaluate the criterion validity of the LI-IATs.

Considering that all participants are resident in a geographic area that is either European and Mediterranean, it was expected that:

(H1) The self-concept is more automatically associated with European landscapes rather than with Not-European ones;

(H2) The self-concept is more automatically associated with Mediterranean landscapes rather than with Not-Mediterranean ones.

Both European and Mediterranean LI-IATs were hypothesized to be significantly correlated with a closer criterion. Thus, it was expected that: 
(H3) The automatic identification with European Landscapes is significantly related to a self-rating measure of European place identity;

(H4) The automatic identification with Mediterranean Landscapes is significantly related to a self-rating measure of Mediterranean place identity.

\section{MATERIALS AND METHODS}

One hundred and seventy four participants, 56\% females and 44\% males, with a mean age of $32.94(S D=9.57)$, were recruited in Rome and Cagliari, which are the main urban agglomerations of, respectively, Lazio and Sardinia, i.e., two Italian Regions bordering on the Mediterranean sea. Concerning the education level, $5 \%$ of the sample attended the Junior High School, 36\% the Senior High School, and 59\% had a Degree.

Participants had to perform two IAT tasks, one devoted to measure the European LI and the other Mediterranean LI, including both images and words as stimuli. After the completion of the IATs, participants filled in a questionnaire including an adaptation of the self-categorization tool consisting in two items, one including the concepts of Self and Europe, the other including the concepts of Self and Mediterranean. Successively, participants had to assess on a self-report scale the pleasantness of all images presented in the IATs.

\section{Landscape Identity IATs (LI-IATs)}

In order to measure the implicit level of European and Mediterranean Landscape Identity, two IATs were developed, with both single and combined categorization tasks, using for each category (Self vs. Other) four stimulus-words (used by Schultz et al., 2004; see Table 1) that were presented in a randomized order within each block of trials. The experimental tasks were performed by means of a $13^{\prime \prime}$ screen laptop. The set of stimuli selected for the IAT tasks included 16 landscape images, i.e., four for each target of the two IAT tasks (European vs. Not European, Mediterranean vs. Not Mediterranean), balanced for natural vs. built landscapes. For the selection of the 16 images, three steps were followed. In the first step, it was chosen a first set of 120 images, i.e., 30 images (15 of them depicting natural environments and 15 of them depicting built environments) for each of the four poles Mediterranean vs. Not Mediterranean and European vs. Not European, on the basis of their supposed fit with the targets. In the second step, a sample of two hundred European residents of different European countries, with a mean age of 32 years $(S D=11.72)$, participated to an online pilot study.

TABLE 1 | The eight stimulus-words used in the LI-IATs.

\begin{tabular}{ll}
\hline Self & Other \\
\hline I & It \\
Me & Other \\
Mine & Their \\
Myself & Them
\end{tabular}

They were instructed to focus on the depicted place (and not on the content of the picture, following the suggestions of Scott and Canter, 1997), and then to rate the degree to which each landscape is prototypical of European vs. Not European, Mediterranean vs. Not Mediterranean, and Natural vs. Built scenarios, using three 5-point semantic differential scales (i.e., ranging from, respectively, "European" to "Not European," "Mediterranean" to "Not Mediterranean," and "Natural" to "Built" environment). Their ratings produced the selection of the 32 most prototypical pictures, i.e., eight for each of the four poles. In the third step, three landscape architects selected the final set of 16 stimuli (four for each category, balanced for natural vs. built). The four sets of stimuli are reported from Figures 1-4.

As described by Greenwald et al. (1998), the entire procedure consisted of seven blocks of trials: a single target categorization task (Self vs. Other; 20 trials for both LI-IATs), a single attribute categorization task (European vs. Not European for the first IAT and Mediterranean vs. Not Mediterranean for the second one; 20 trials), an initial combined categorization task (i.e., Self or European vs. Other or Not European for the first IAT; Self or Mediterranean vs. Other or Not Mediterranean for the second IAT; two sub-blocks of 20 and 40 trials, respectively), a single target categorization task reversed (e.g., Other vs. Self, 20 trials) and a second combined categorization task (i.e., Other or European vs. Self or Not European and Other or Mediterranean vs. Self or Not Mediterranean; two sub-blocks of 20 and 40 trials, respectively). The order of the two combined blocks was counterbalanced across participants (no order effects were found).

Data from the combined blocks were used to compute the value-IATs D scores, according to the built-in error penalty procedure (Greenwald et al., 2003).

\section{Explicit Place Identity}

Both self-categorization items (see Bergami and Bagozzi, 2000; Schultz, 2001), adapted for measuring Mediterranean and European identification (Aron et al., 1992), are composed of eight figures, each one representing two circles in a continuum from the first figure (where the two circles are far apart) to the last figure (where the two circles are overlapped). Participants had to choose the figure that best reflects the closeness between their Self and, respectively, Europe in the first item and Mediterranean in the second item. Figure 5 reports the two items, including the instructions for the participants.

\section{Pleasantness of Landscape Images}

Participants rated the pleasantness of the 16 landscape pictures presented in the IATs on a five-point Likert scale, ranging from 1 (unpleasant) to 5 (pleasant). Global measures of landscape pleasantness were computed summing up European, not European, Mediterranean, and not Mediterranean scores separately. Differences between European vs. Not European and Mediterranean vs. not Mediterranean scores were computed in order to use a measure of pleasantness structurally similar to the IAT. 


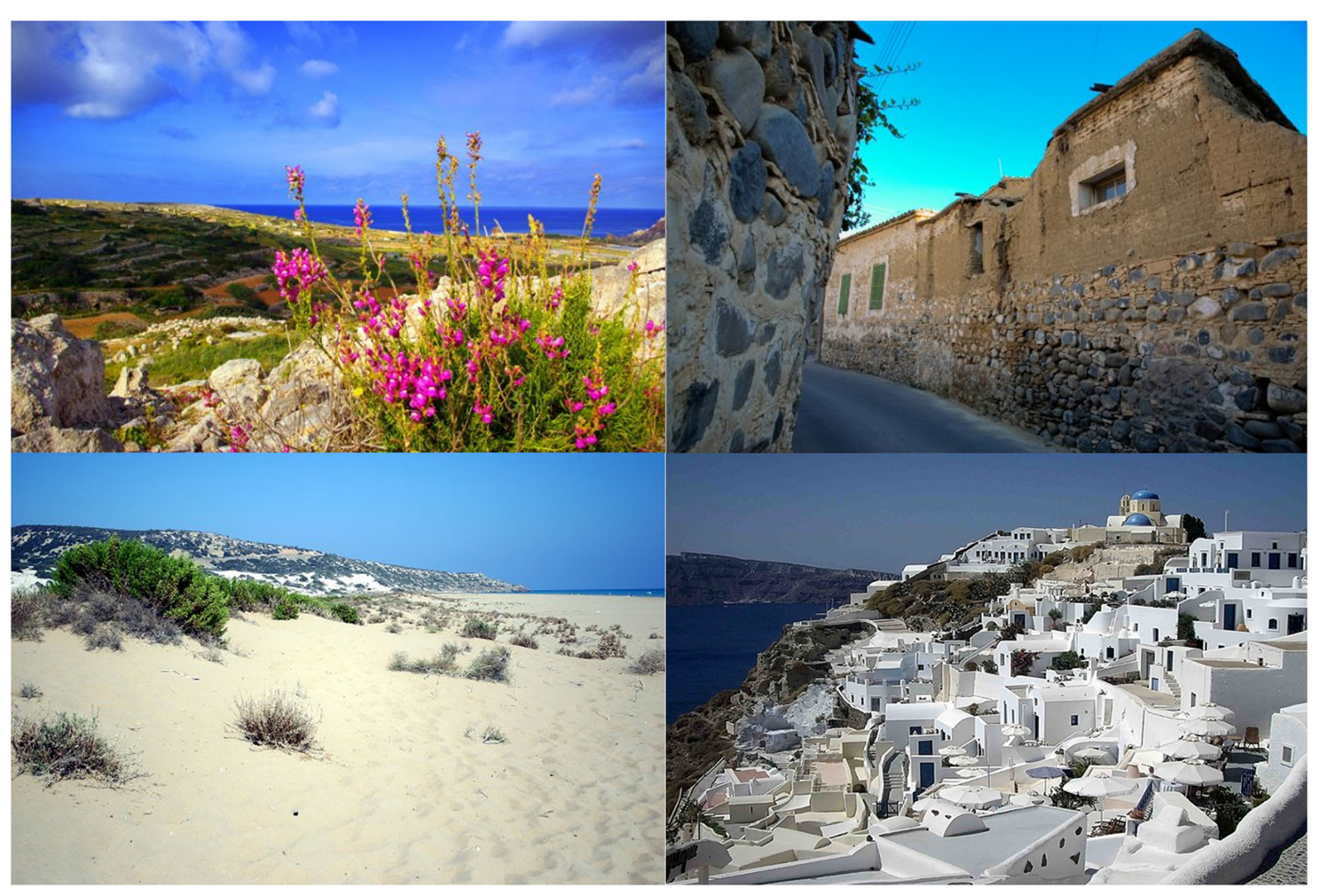

FIGURE 1 | The four Mediterranean images used for the Mediterranean vs. Not-Mediterranean LI-IAT.

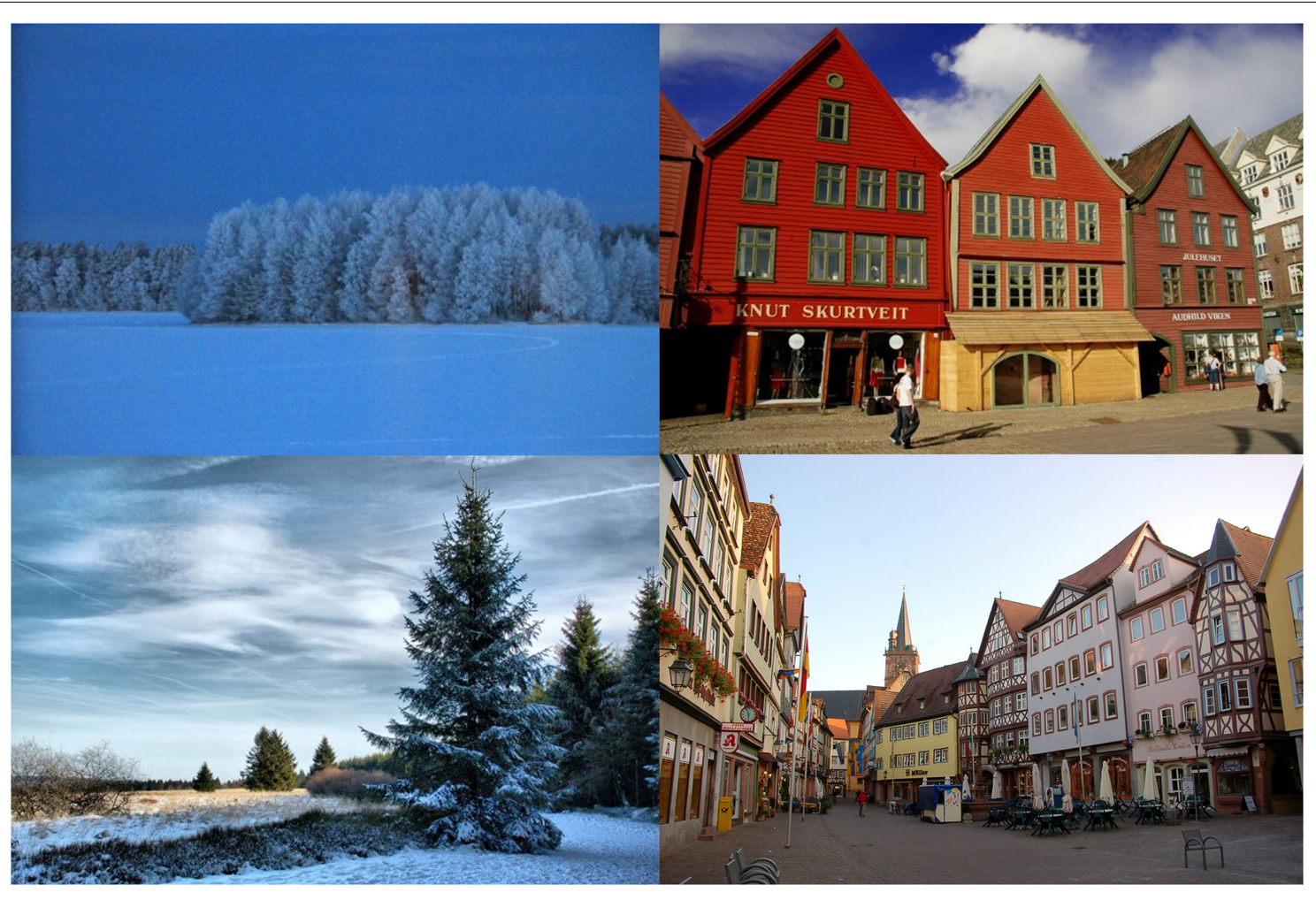

FIGURE 2 | The four Not-Mediterranean images used for the Mediterranean vs. Not-Mediterranean LI-IAT. 


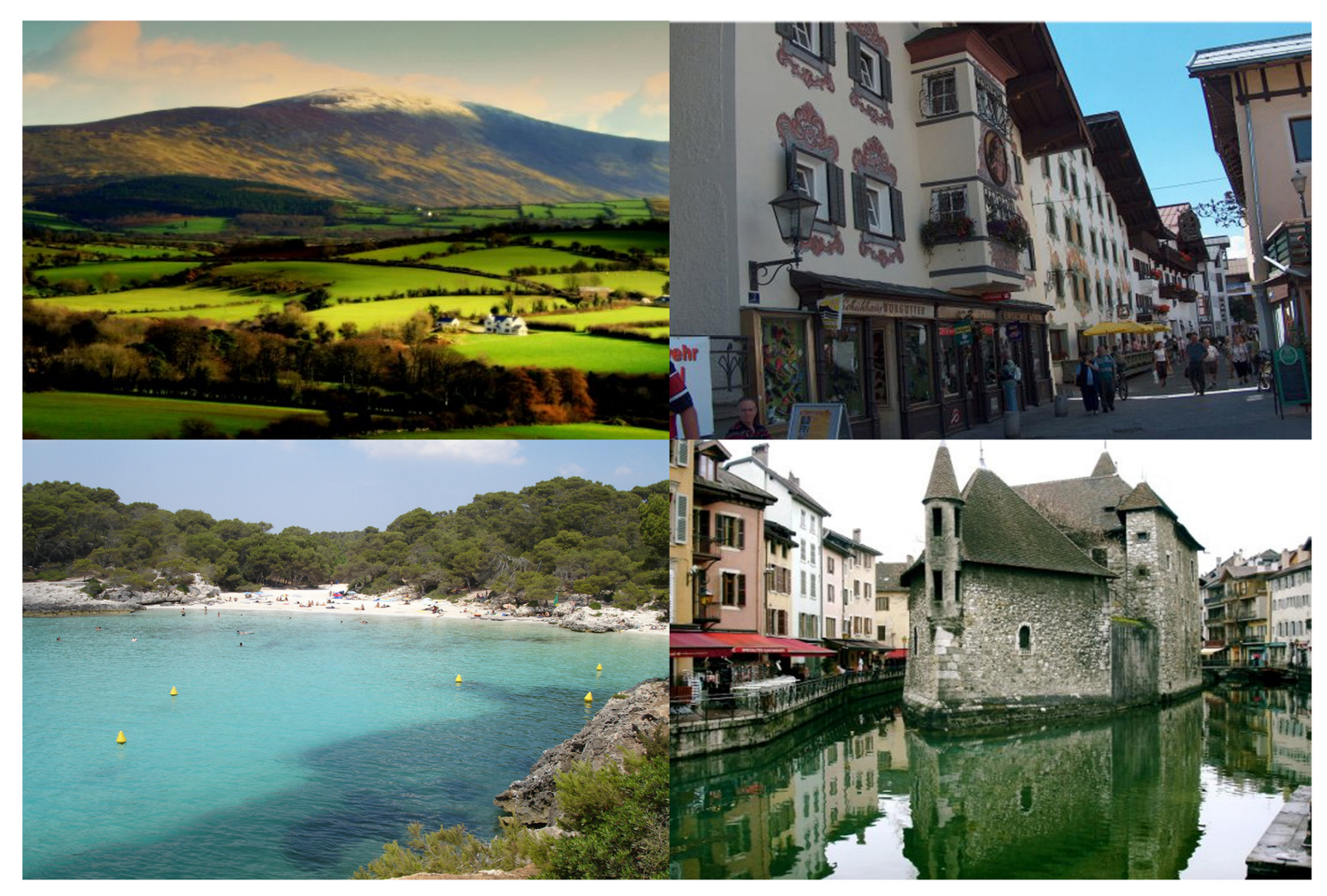

FIGURE 3 | The four European images used for the European vs. Not-European LI-IAT.

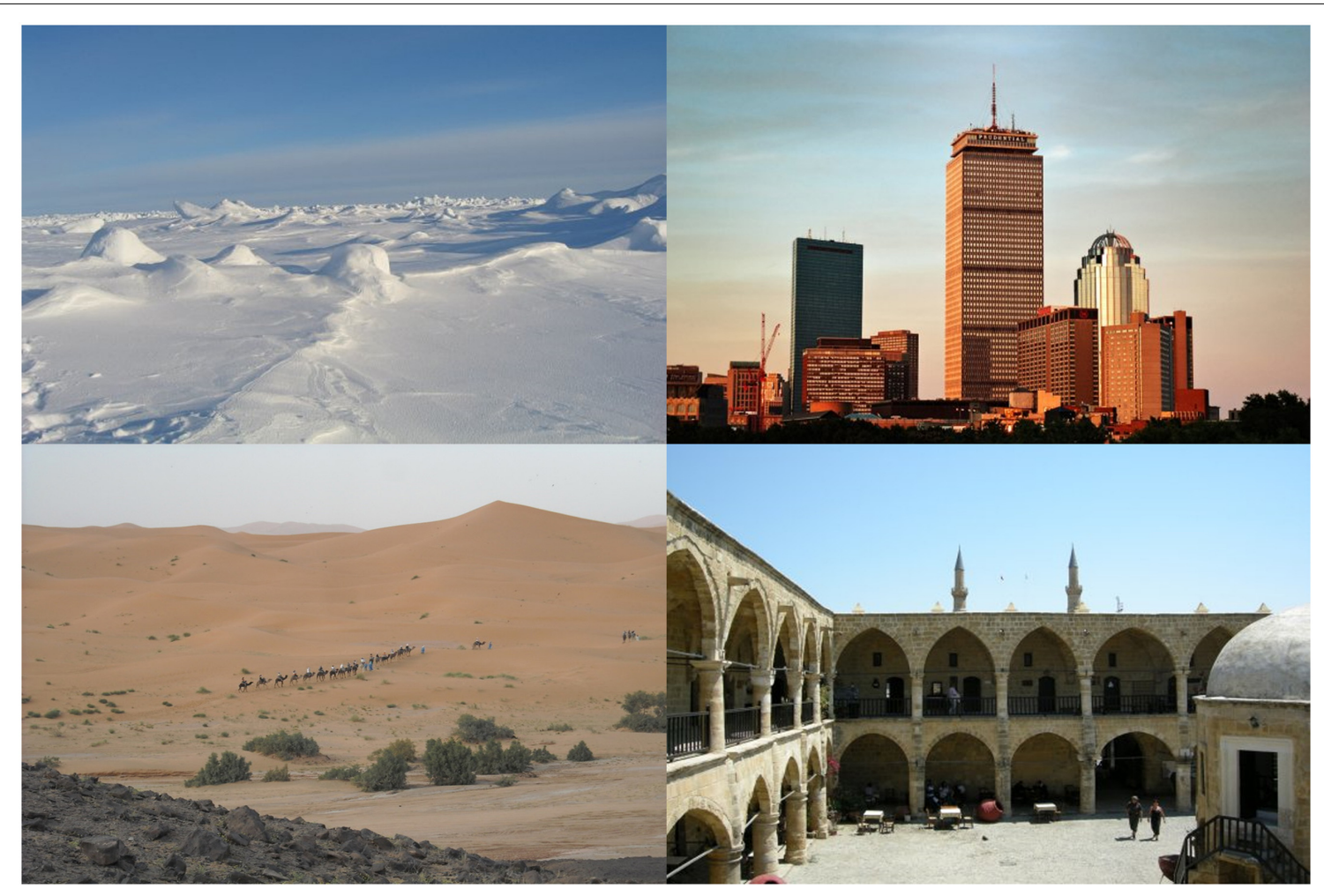

FIGURE 4 | The four Not-European images used for the European vs. Not-European LI-IAT. 
Please focus on Europe. The first circle represents your identity and the second circle represents Europe. Flag the square that better describes the level of overlap between you and Europe.
Please focus on Europe. The first circle represents your identity and the second circle represents Europe. Flag the square that better describes the level of overlap between you
and Europe.
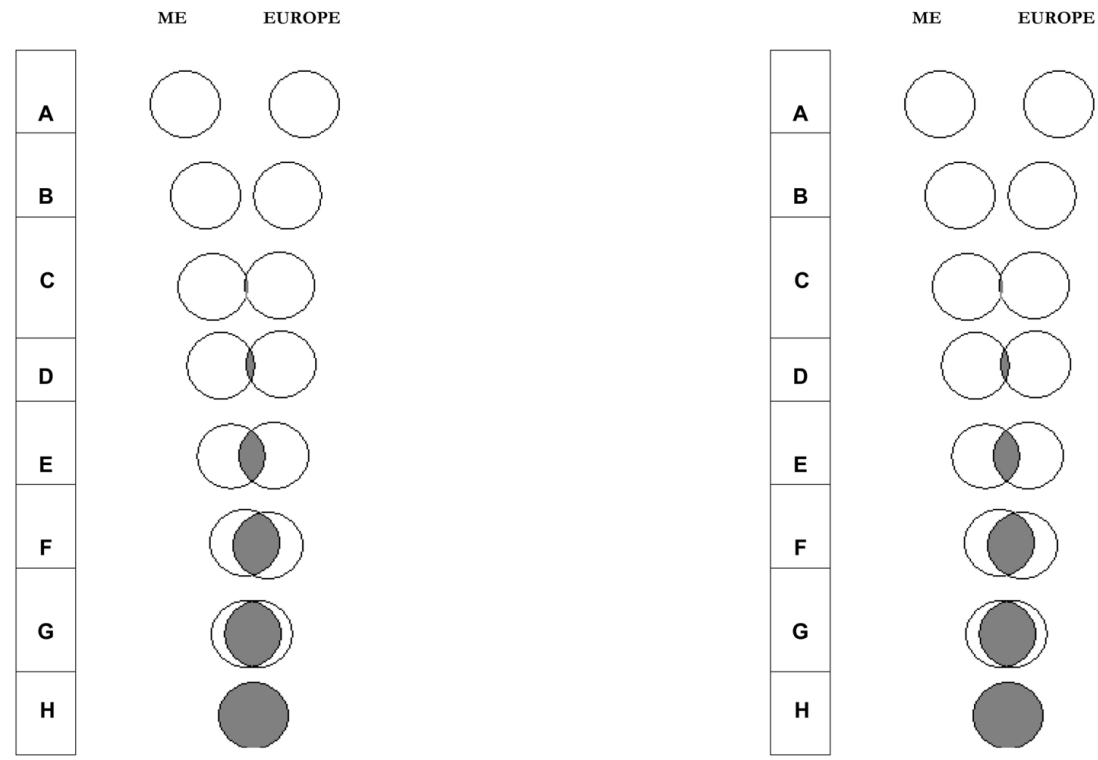

FIGURE 5 | The two graphic items measuring, respectively, European and Mediterranean explicit place identity.

\section{RESULTS}

\section{Internal Consistency of LI-IATs and Descriptive Statistics}

As reported in Table 2, both implicit and explicit measures showed skewness and kurtosis parameters included between \pm 1 , indicating that their distribution is approximately normal. The internal consistency of the IATs was computed with a split-half estimation (Spearman-Brown corrected) using two partial D scores calculated on blocks 3-6 and 4-7, respectively. Both IATs showed an adequate level of reliability: $r_{\mathrm{sp}}=0.70$ for European IAT and $r_{\mathrm{sp}}=0.76$ for Mediterranean IAT.

Landscape Identity IATs and the other measures were not significantly correlated with participants' age. Differently, some significant gender differences emerged, with a higher mean score for males than females on both Mediterranean place identity [mean difference $=-0.48 ; t(170)=-2.00$, $p<0.05$ ] and pleasantness attributed to the Mediterranean [mean difference $=-0.34 ; t(170)=-2.27, p<0.05$ ].

Moreover, the correlations of the Mediterranean and the European LI-IATs with the corresponding place identity scales were, respectively, significant $(r=0.37, p<0.001)$ and close to be significant $(r=0.15, p=0.06)$. Both the LIIATs were not correlated with the pleasantness evaluation of landscapes. The pleasantness attributed to Mediterranean landscapes was significantly correlated with Mediterranean place identity $(r=0.17, p<0.05)$ while a not significant correlation emerged between the pleasantness of European landscapes and European place identity.

\section{Testing $\mathrm{H} 1$ and $\mathrm{H} 2$ : Comparison of LI-IATs Means with the Neutral Scale Point}

As expected, mean scores of both LI-IATs were positive (see Table 1) and significantly different from zero $[t(171)=22.29$, $p<0.001$ for the Mediterranean IAT; $t(168)=25.56, p<0.001$ for the European IAT] with large effect sizes (Cohen's $D=1.70$ for the Mediterranean IAT and Cohen's $D=1.95$ for the European IAT), indicating that European and Mediterranean landscapes were evaluated as more associated with the self if compared to Not European and Not Mediterranean ones. These results confirm, respectively, $\mathrm{H} 1$ and $\mathrm{H} 2$.

\section{Testing $\mathrm{H} 3$ and H4: Relationships between the LI-IATs and Explicit Place Identity}

In order to further investigate the relationship between the LIIATs and explicit place identity, two regression analyses were conducted. In the first one, the IAT measure of European place identity was included as a predictor, the self-report measure of European place identity as a criterion, and both gender and pleasantness of European landscapes as controls ${ }^{1}$. Similarly, in the second one, the IAT measure of Mediterranean place identity was included as a predictor, the self-report measure of Mediterranean place identity as a criterion and, again, gender and pleasantness of Mediterranean landscapes as controls. Gender and pleasantness of landscapes were included as covariates

\footnotetext{
${ }^{1}$ In both regression analyses, age was not included as a covariate since it was not
} significantly related to both explicit place identities and LI-IATs. 
TABLE 2 | Descriptive statistics.

\begin{tabular}{|c|c|c|c|c|}
\hline & Mean & $S D$ & Skewness & Kurtosis \\
\hline IAT_eu & 0.74 & 0.38 & -0.43 & 0.34 \\
\hline IAT_med & 0.75 & 0.44 & -0.70 & 0.66 \\
\hline Eu_identity & 4.70 & 1.58 & -0.53 & -0.07 \\
\hline Med_identity & 6.10 & 1.52 & -0.70 & 0.18 \\
\hline Pleasantness_eu & -0.99 & 2.68 & 0.16 & -0.19 \\
\hline Pleasantness_med & -0.67 & 1.95 & -0.19 & 0.43 \\
\hline
\end{tabular}

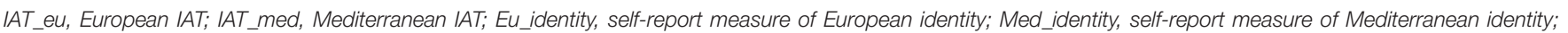

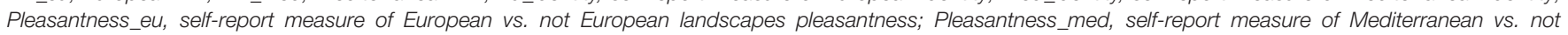
Mediterranean landscapes pleasantness.

in order to control for their effect on place identity (see Discussion). Results showed a significant relationship of small size between European LI-IAT and European place identity $\left(R^{2}=0.023 ; \beta=0.15, p<0.05\right)$, whereas the effects of gender and pleasantness of European landscapes were not significant. A stronger significant relationship of moderate size emerged between Mediterranean LI-IAT and Mediterranean place identity $\left(R^{2}=0.13 ; \beta=0.36, p<0.01\right)$, with significant effects of gender $(\beta=-0.17, p<0.05)$ and pleasantness of European landscapes $(\beta=0.18, p<0.05)$. These results give a first evidence for the criterion validity of the LI-IATs.

\section{DISCUSSION}

This study was aimed at applying the IAT to measure European and Mediterranean landscape identity. In particular, we focused on the evaluation of the psychometric properties and criterion validity of the LI-IATs. Results showed a high split-half correlation (Spearman-Brown corrected) for both the LI-IATs, providing a first evidence for their adequate reliability. Moreover, as expected, considering that all participants are resident in geographical areas that are either European and Mediterranean, the mean $D$-scores were positive and significantly different from zero, suggesting that prototypical images of European and Mediterranean landscapes are more associated with the Self compared to, respectively, not European and not Mediterranean pictures. These results confirmed the first two hypotheses of the study, supporting the adequacy of the prototypical landscapes selected as stimuli. Finally, European and Mediterranean LI-IATs were, respectively, related to European and Mediterranean social identity, also when the pleasantness of the landscapes was controlled for. Notably, the effect size was larger for the Mediterranean LI-IAT rather than for the European one. This difference may be due to the different capacity of the European and Mediterranean landscapes to represent the corresponding categories. Indeed, since the latter area is more geographically homogeneous than the former one, the capacity of the Mediterranean landscapes to represent the corresponding area is higher with respect to the capacity of the European ones, which are much more varied and, above all, intercepts only a specific aspect of the rich and articulated meaning of the Europe notion. Overall, notwithstanding the differences found, these results support the criterion validity of both European and Mediterranean LIIATs.

Interestingly, using the LI-IATs, other studies with experimental or longitudinal designs may be conducted in order to investigate if the specificity of the European landscapes, despite its variety, may enhance the feeling of belongingness to Europe in its citizens, as hoped by Habermas (1998). In fact, considering the significant correlations found between the LI-IATs and European and Mediterranean place identity (here conceived as "localized" social identities, see also Valera and Pol, 1994), such images are expected to convey social meanings (see Twigger-Ross et al., 2003) that go beyond the depicted scenes, including historical memories, cultural heritage, and direct and/or indirect experiences. Pictures of a recognizable European landscape may thus be able to promote a positive identification with Europe in European citizens, as found in a cross-cultural study run in diverse Italian and Spanish regions (Fornara et al., submitted). This would support a positive place identity process, as postulated by Carrus et al. (2014), and help higher community identification with the Europe concept. In other words, the feeling of "Europeanness" (Wodak, 2004) may be fostered by putting the landscape into the foreground.

Similarly, on the basis of the present results, future studies with experimental or longitudinal designs may use the LI-IAT to investigate the degree to which the Mediterranean landscapes can influence the identification with the Mediterranean. In fact, even though in this case it is not present a socio-political entity (as for Europe) that can be perceived as a reference target, the Mediterranean typical traits (see Petruzzellis and Craig, 2014) seem to be well reflected also by the landscape. It is not surprising that the internationally acknowledged beauty and pleasantness of typical Mediterranean scenes, which are commonly used to attract tourism, are elements of proudness for those who live in the Mediterranean area. For that reason, consistently with the SIT (Tajfel and Turner, 1986), such elements may represent important markers of a positive social identity related to the Mediterranean belongingness.

Even though our findings provide evidence for the adequacy of the landscapes selected and the criterion validity of the LI-IATs, some limitations of this study need to be reported.

A first limitation is the sample recruitment at national level only, that does not allow an evaluation of the LI-IATs capacity to detect possible differences across residents in different European and Mediterranean geographical areas. Thus, we cannot exclude 
that residents of different European countries may differ in their responses to European landscapes. In a similar vein, the identification with the Mediterranean may be less pronounced in French residents, as found by Petruzzellis and Craig (2014), and not predictable for residents in non-European countries, such as North African or Near East countries. Future cross-cultural research is thus needed in order to further validate these tools in other European and Mediterranean countries.

A methodological limit regards the measurement of the automatic level of landscape identity, that is exclusively based on the classical IAT paradigm. In future studies, it may be important to test the convergent validity of the LI-IAT developing other implicit measures of landscape identity, using for instance the Single Category IAT (Karpinski and Steinman, 2006).

A further point that needs to be mentioned concerns the partial conceptual overlap, in literature, of place-identity and other place-related constructs (see Fornara et al., 2010), such as place attachment (Altman and Low, 1992), place dependence (Stokols and Shumaker, 1981), place belongingness (Korpela, 1989), rootedness (Relph, 1976), sense of place (Hummon, 1992), and sense of community (Perkins et al., 1990), just to name a few. Nevertheless, the theoretical debate around similarities and differences among these constructs and how they are operationalized are beyond the aims of this manuscript.

\section{CONCLUSION}

This study used the IAT to measure Mediterranean and European landscapes identities. Results showed that: (i) internal consistency of the two LI-IATs is adequate; (ii) participants identify themselves more with European or Mediterranean landscapes rather than with those landscapes that are, respectively, Not European or Not Mediterranean; and (iii) implicit European

\section{REFERENCES}

Abrams, D., and Emler, N. (1992). Self denial as a paradox of political and regional social identity: findings from a study of 16-and 18-year olds. Eur. J. Soc. Psychol. 22, 279-295. doi: 10.1002/ejsp.2420220306

Altman, I., and Low, S. (1992). Place Attachment. New York, NY: Plenum.

Aretano, R., Petrosillo, I., Zaccarelli, N., Semeraro, T., and Zurlini, G. (2013). People perception of landscape change effects on ecosystem services in small Mediterranean islands: a combination of subjective and objective assessments. Landsc. Urban Plan. 112, 63-73. doi: 10.1016/j.landurbplan.2012. 12.010

Aron, A., Aron, E. N., and Smollan, D. (1992). Inclusion of other in the self scale and the structure of interpersonal closeness. J. Pers. Soc. Psychol. 63, 596-612. doi: 10.1037/0022-3514.63.4.596

Aubenas, F., and Benasayag, M. (2002). Résister C'est Créer. Paris: La Découverte.

Bergami, M., and Bagozzi, R. P. (2000). Self-categorization, affective commitment and group self-esteem as distinct aspects of social identity in the organization. Br. J. Soc. Psychol. 39, 555-577. doi: 10.1348/014466600164633

Bonnes, M., Passafaro, P., and Carrus, G. (2011). The ambivalence of attitudes toward urban green areas: between proenvironmental worldviews and daily residential experience. Environ. Behav. 43, 207-232. doi: 10.1177/0013916509354699

Brügger, A., Kaiser, F. G., and Roczen, N. (2011). One to bind them all Connectedness to nature, environmental identity, and implicit association with nature. Eur. Psychol. 1, 1-10. and Mediterranean landscape identities are related, respectively, to explicit European and Mediterranean place identities, even when pleasantness of landscapes is controlled for. These results support the validity of the LI-IATs and confirm that European and Mediterranean landscapes may be used as scenarios of identification, even though they represent larger geographical scales if compared to those usually investigated in similar studies (e.g., see Hernández et al., 2007; Lewicka, 2010).

In conclusion, this study provides a first evidence for the reliability and criterion validity of the LI-IATs, opening new ways for understanding the nature of landscape identification, along with the mechanisms that underlie its activation and development.

\section{AUTHOR CONTRIBUTIONS}

FF developed the research idea (together with RT), led its preparation and realization, and is the main contributor of the paper writing (in terms of both structure and content). FD participated to the preparation of the research design, made the data elaboration, and is the main contributor of the results section, playing also an important role for the writing of the other sections. RT developed the research idea (together with FF) and played an important part in the various phases of stimuli selection and in the supervision of the data collection phase. SP played an important part in the data collection and in the review of the reference literature.

\section{ACKNOWLEDGMENT}

We wish to thank Carlotta Zoncu for her valuable help in the data collection phase.

Carrus, G., Bonaiuto, M., and Bonnes, M. (2005). Environmental concern, regional identity, and support for protected areas in Italy. Environ. Behav. 37, 237-257. doi: 10.1177/0013916504269644

Carrus, G., Scopelliti, M., Fornara, F., Bonnes, M., and Bonaiuto, M. (2014). "Place attachment, community identification, and pro-environmental engagement," in Place Attachment. Advances in Theory, Methods and Applications, eds L. C. Manzo and P. Devine-Wright (New York: Routledge), 154-164.

Cassano, F. (1998). Il Pensiero Meridiano, Vol. 362. Bari: Laterza.

Clayton, S. (2003). "Environmental identity: a conceptual and an operational definition," in Identity and the Natural Environment, eds S. Clayton and S. Opotow (Cambridge, MA: MIT Press), 45-65.

Dentale, F., Vecchione, M., De Coro, A., and Barbaranelli, C. (2012). On the relationship between implicit and explicit self-esteem: the moderating role of dismissing attachment. Pers. Individ. Differ. 52, 173-177. doi: 10.1016/j.paid.2011.10.009

Dinan, D. (2004). Europe Recast: A History of European Union. Basingstoke: Palgrave Macmillan.

European Environment Agency (2011). Land Take. Available at: http://www.eea. europa.eu/data-and-maps/indicators/land-take-2, (accessed March 14, 2015).

European Landscape Convention (2000). European Landscape Convention. Available at: http://www.coe.int/web/landscape (accessed March 14, 2015).

Fabre, T. (1998). "Le noir et le bleu," in Méditerranées, eds M. Le Bris and J. C. Izzo (Paris: Librio), 9-12.

Fornara, F., Bonaiuto, M., and Bonnes, M. (2010). Cross-validation of abbreviated Perceived Residential Environment Quality (PREQ) and 
Neighbourhood Attachment (NA) indicators. Environ. Behav. 42, 171-196. doi: $10.1177 / 0013916508330998$

Gawronski, B., and Payne, B. K. (eds) (2010). Handbook of Implicit Social Cognition: Measurement, Theory, and Applications. New York, NY: Guilford Press.

Greenwald, A., Mcghee, D. E., and Schwartz, J. L. K. (1998). Measuring individual differences in implicit cognition: the implicit association test. J. Pers. Soc. Pychol. 74, 1464-1480. doi: 10.1037/0022-3514.74.6.1464

Greenwald, A. G., Nosek, B., and Banaji, M. (2003). Understanding and using the implicit association test: I. An improved scoring algorithm. J. Pers. Soc. Psychol. 85, 197-216. doi: 10.1037/0022-3514.85.2.197

Guarracino, S. (2007). Mediterraneo: Immagini, Storie E Teorie Da Omero A Braudel. Milano: Bruno Mondadori.

Habermas, J. (1998). "Three normative models of democracy," in The Inclusion of the Other, ed. J. Habermas (Cambridge, MA: Massachusetts Institute for Technology Press), 239-252.

Hagerhall, C. M. (2001). Consensus in landscape preference judgments. J. Environ. Psychol. 21, 83-92. doi: 10.1016/j.jenvman.2014.02.009

Hernández, B., Hidalgo, M. C., Salazar-Laplace, M. E., and Hess, S. (2007). Place attachment and place identity in natives and non-natives. J. Environ. Psychol. 27, 310-319. doi: 10.1016/j.jenvp.2007.06.003

Hofmann, W., Gschwendner, T., and Schmitt, M. (2005). On implicit-explicit consistency: the moderating role of individual differences in awareness and adjustment. Eur. J. Pers. 19, 25-49. doi: 10.1002/per.537

Hummon, D. M. (1992). "Community attachment: local sentiment and sense of place," in Place Attachment, eds I. Altman and S. Low (New York, NY: Plenum), 253-278.

Kaltenborn, B. P., and Bjerke, T. (2002). Associations between environmental value orientations and landscape preferences. Landsc. Urban Plan. 59, 1-11. doi: 10.1016/S0169-2046(01)00243-2

Kaplan, R., and Kaplan, S. (1989). The Experience of Nature. New York, NY: Cambridge University Press.

Karpinski, A., and Steinman, R. B. (2006). The single category implicit association test as a measure of implicit social cognition. J. Pers. Soc. Psychol. 91, 16-32. doi: 10.1037/0022-3514.91.1.16

Korpela, K. M. (1989). Place-identity as a product of environmental self-regulation. J. Environ. Psychol. 9, 241-256. doi: 10.1016/S0272-4944(89)80038-6

Lalli, M. (1992). Urban-related identity: theory, measurement, and empirical findings. J. Environ. Psychol. 12, 285-303. doi: 10.1016/S0272-4944(05)80078-7

Lewicka, M. (2008). Place attachment, place identity and place memory: restoring the forgotten city past. J. Environ. Psychol. 28, 209-231. doi: 10.1016/j.jenvp.2008.02.001

Lewicka, M. (2010). What makes neighborhood different from home and city? Effects of place scale on place attachment. J. Environ. Psychol. 30, 35-51. doi: 10.1016/j.jehvp.2009.05.004

Mayer, F. S., and Frantz, C. M. (2004). The connectedness to nature scale: a measure of individuals' feeling in community with nature. J. Environ. Psychol. 24, 503-515. doi: 10.1016/j.jenvp.2004.10.001

Nisbett, R. E., and Wilson, T. D. (1977). Telling more than we can know: verbal reports on mental processes. Psychol. Rev. 84, 231-259. doi: 10.1037/0033295X.84.3.231

Nosek, B. A., Greenwald, A. G., and Banaji, M. R. (2005). Understanding and using the implicit association test: II. method variables and construct validity. Pers. Soc. Psychol. Bull. 31, 166-180. doi: 10.1177/0146167204271418

Olivos, P., and Aragonés, J. I. (2013). Test de asociacionesimplícitas con la naturaleza: aplicación en España del "IAT-Nature". Rev. De Psicol. Soc. 28, 237-245. doi: 10.1174/021347413806196672

Paulhus, D. L. (1991). "Measurement and control of response bias," in Measures of Personality and Social Psychological Attitudes, eds J. P. Robinson, P. R. Shaver, and L. S. Wrightsman (San Diego, CA: Academic Press), 17-59.

Perkins, D. D., Florin, P., Rich, R., Wandersman, A., and Chavis, D. M. (1990). Participation and the social and physical environment of residential blocks: crime and community context. Am. J. Community Psychol. 18, 83-115. doi: 10.1007/BF00922690

Petruzzellis, L., and Craig, C. (2014). Separate but Together: Mediterranean Identity in Three Countries. Available at: http://dx.doi.org/10.2139/ssrn.2528188
Proshansky, H. M. (1978). The city and self-identity. Environ. Behav. 10, 147-169. doi: $10.1177 / 0013916578102002$

Proshansky, H. M., Fabian, A. K., and Kaminoff, R. (1983). Place-identity: physical world socialization of the self. J. Environ. Psychol. 3, 57-83. doi: 10.1016/S02724944(83)80021-8

Relph, E. (1976). Place and Placelessness. London: Pion Ltd.

Schneider, B. (1987). The people make the place. Pers. Psychol. 40, 437-453. doi: 10.1111/j.1744-6570.1987.tb00609.x

Schultz, P., Shriver, C., Tabanico, J. J., and Khazian, A. M. (2004). Implicit connections with nature. J. Environ. Psychol. 24, 31-42. doi: 10.1016/S02724944(03)00022-7

Schultz, P., and Tabanico, J. (2007). Self, identity, and the natural environment: exploring implicit connections with nature. J. Appl. Soc. Psychol. 37, 1219-1247. doi: $10.1111 / j .1559-1816.2007 .00210 . x$

Schultz, P. W. (2001). Assessing the structure of environmental concern: concern for the self, other people, and the biosphere. J. Environ. Psychol. 21, 327-339. doi: 10.1006/jevp.2001.0227

Scott, M. J., and Canter, D. V. (1997). Picture or place? A multiple sorting study of landscape. J. Environ. Psychol. 17, 263-281. doi: 10.1006/jevp.1997. 0068

Smith, A. D. (1992). National identity and the idea of European Unity. Int. Aff. 68, 55-76. doi: $10.2307 / 2620461$

Stanners, D., and Bourdeau, P. (1995). Europe's Environment the Dobris Assessment. Copenhagen: European Environment Agency.

Stokols, D., and Shumaker, S. A. (1981). "People in places: a transactional view of settings," in Cognition, Social Behavior and Environment, ed. J. Harvey (Hillsdale, NJ: Erlbaum).

Tajfel, H., and Turner, J. C. (1986). "The social identity theory of intergroup behaviour," in Psychology of Intergroup Relations, eds S. Worchel and W. G. Austin (Chicago: Nelson-Hall).

Tarrius, A. (1992). Les Fourmisd'Europe. Paris: L'Harmattan.

Truelove, H. B., Greenberg, M. R., and Powers, C. W. (2014). Are implicit associations with nuclear energy related to policy support? Evidence from the brief implicit association test. Environ. Behav. 46, 898-923. doi: $10.1177 / 0013916513480861$

Twigger-Ross, C., Bonaiuto, M., and Breakwell, G. M. (2003). Identity Theories and Environmental Psychology. Aldershot: Ashgate, 203-234.

Uzzell, D., Pol, E., and Badenas, D. (2002). Place identification, social cohesion, and environmental sustainability. Environ. Behav. 34, 26-53. doi: $10.1177 / 0013916502034001003$

Valera, S., Guàrdia, J., and Pol, E. (1998). A study of the symbolic aspects of space using non quantitative techniques of analysis. Qual. Quant. 32, 367-381. doi: 10.1023/A:1004360609319

Valera, S., and Pol, E. (1994). El concepto de identidad social urbana: una aproximación entre la psicología social y la psicología ambiental. Anu. De Psicol. $62,5-24$.

Vecchione, M., Dentale, F., Alessandri, G., and Barbaranelli, C. (2014). Fakability of implicit and explicit measures of the big five: research findings from organizational settings. Int. J. Select. Assess. 22, 211-218. doi: 10.1111/ijsa. 12070

Wodak, R. (2004). "National and transnational identities: European and other identities constructed in interviews with EU officials," in Transnational Identities: Becoming European in the EU, eds R. Herrmann, T. Risse, and M. Brewer (Lanham, MD: Rowman and Littlefield).

Conflict of Interest Statement: The authors declare that the research was conducted in the absence of any commercial or financial relationships that could be construed as a potential conflict of interest.

Copyright ( 2016 Fornara, Dentale, Troffa and Piras. This is an open-access article distributed under the terms of the Creative Commons Attribution License (CC BY). The use, distribution or reproduction in other forums is permitted, provided the original author(s) or licensor are credited and that the original publication in this journal is cited, in accordance with accepted academic practice. No use, distribution or reproduction is permitted which does not comply with these terms. 